\title{
Research on Practical Significance and Realization Path of the Cultivation of College Sports Spirit
}

\author{
Bo Yao \\ Dalian Maritime University, Dalian, 116026, China
}

Keywords: College Sports Spirit, Sportsmanship, Sports Culture

\begin{abstract}
The college sport spirit is the spiritual wealth and strength that is created and continued around sports in the environment of the college. The cultivation of college physical education spirit can enhance the physical quality, cultivate the healthy personality and improve the moral cultivation of college students. In the new period, to cultivate the sport spirit in colleges, we should construct the sports culture atmosphere, innovate sports teaching methods and the improve sports management system.
\end{abstract}

\section{Introduction}

As a cultural phenomenon in the human society, sports play an important role in the social development, and its charm and influence far exceed the sport itself. Sports spirit is the highest product of sports. It advocates the spirit of people-oriented, fair and just, seeking truth from facts, solidarity and cooperation, striving for progress and pioneering spirit, which is exactly what university talents need now. University is not only an objective material existence, but also a kind of cultural existence and spiritual existence. The spirit and core of the university is the soul and core of the University. It is the fundamental and fundamental place of the University, which is related to the survival and development of the University. In recent years, China's higher education has made great progress. But with the intensification of social transformation and the rapid development of market economy, universities are facing many crises and challenges at the same time of rapid development. From the face of the temptations of the outside world and pressure, coupled with the inherent contradiction, college market, utilitarian and secular tendency is becoming more and more serious, the university spirit gradually lost and declining, especially in the humanistic spirit of landslide, part of the university social responsibility consciousness is weak, the lack of moral belief. Entering the twenty-first Century, China's higher education has entered the critical period of development and reform. It has put forward higher requirements for the training of talents. Especially the call for innovative talents has never been so urgent. Sports spirit refers to a mental outlook and cohesion formed in the process of sports development. It reflects the idea and belief of sports and the corresponding motive force of sports development through the development of sports. From the present point of view, sports spirit also includes the mental activities of athletes and sports learners, such as appearance and mentality. It is a correct attitude towards sports concept.

\section{Practical Significance of the Cultivation of College Sports Spirit}

\subsection{Enhance Physical Quality}

Along with China's per capita life level rising, the growth of college students' environment has been greatly improved, the physical quality of college students should be improved, but the actual situation is just the opposite, overweight has become a healthy student groups in China one of the main factors. As the hope and future of our country, it is urgent for us to improve the physical quality of college students. We should actively encourage college students to invest in sports activities, and strengthen physical exercise has become one of the core goals of university education. Physical 
quality refers to the body's basic state and functional ability, such as strength, speed, stamina, and so on. Fitness and health are similar but not identical, have their own connotation and constitution as determiners for the integration of health physical health, expand the connotation of health, reduce health extension, can better distinguish three-dimensional health physical health, mental health, social adaptation concept, emphasize that in the physical body structure, physiological function and psychological factors on health. Physical and mental health can reflect a person's physical quality. In turn, the physical quality can also reflect a person's physical health. Therefore, physical quality is an important form of physical health and an important part of physical health. The continuous decline of College Students' physical fitness can reflect the continuing decline of College Students' physical health. There is a causal relationship between the occurrence and the occurrence of any event. Only when we think deeply about the reasons for the continuous decline of College Students' physical quality, can we take practical measures for the problems that arise. Only by cultivating the spirit of physical education can we change the status of the continuing decline of College Students' physical quality.

\subsection{Develop Healthy Personality}

To cultivate the students' sports spirit is of great importance and value for the students to form a healthy personality. On the one hand, through physical exercise, students' sense of rules can be enhanced, no matter what sports competitions are based on certain rules, and all sports participants must abide by them. Therefore, the training of the students' Sports Spirit helps to enhance the students' awareness of the rules and help to develop a healthy personality. On the other hand, the cultivation of sports spirit can also promote the capital of college students to have success and happiness. Only a healthy body can achieve success and happiness. There are various criteria for success and happiness, but the core of it is to have healthy physical quality, without healthy body, and all in vain. It is well known that the goal of mental health is the integrity of the personality. The first sign of the integrity of personality is: all elements of personality structure must be complete, harmonious and unified. That the core of personality is to take a positive outlook on life and the world as a basis, and integrate their wishes, behaviors and goals on this basis. As we all know, in China's major universities, through various sports competitions and flexible teaching activities, students develop rules to regulate their behavior habits. At the same time, through the sports spirit, it has a fair and objective perspective, and to analyze and solve problems, to guide its own clear goal in sports, and establish their own reasonable goal, correct attitude towards sports activities and competition and meet all the challenges of life, work or study with a positive attitude. Therefore, the sports spirit can promote the students to form a complete personality to a certain extent.

\subsection{Optimize Moral Cultivation}

The spirit of physical education is conducive to the cultivation of College Students' true and practical qualities, as well as honesty and discipline. As everyone knows, sports and life, not opportunistic, make false, require all the contestants must be honest and trustworthy, pragmatic. In the Olympics, you can only use fast legs and strength to overcome your opponent. Money can't be your victory. In the modern Olympic Games, the idea of equality, competition and the equality before the rules is still one of the core of the spirit of sports. Therefore, the spirit of sports is conducive to the cultivation of College Students' realistic and pragmatic, collective concept and good moral character of honesty and discipline. Secondly, the spirit of sports is conducive to the cultivation of College Students' collectivism. Some people think that sports is a kind of competitive activity, it is an important means to train the students' competitive consciousness, and it is the goal of defeating the opponent to win the victory. In fact, there is a clear misunderstanding here. Sports is also an effective way to cultivate the cooperative consciousness of the individual and to obtain the harmony and unity between the two. Practice has proved that a good sports team not only requires athletes to have superb competitive skills and excellent sports talents, but also requires the team of athletes to provide a collective atmosphere for their ability to excavate and display. Sports, in a unique way, enables us to establish collective consciousness and let us understand in the collective cooperation and competition. 
Only when we integrate the power of individuals, can we become strong. Therefore, the spirit of sports is conducive to the cultivation of the concept of collectivism of college students. College students must abide by the rules of adjudication when they participate in sports, and they will be punished if they break the rules. They are rewarded accordingly, and face up to the process of understanding and imitating their social civilization. Therefore, the combination of sports spirit contained in sports culture and the discipline cultivation of college students has a profound influence on strengthening the discipline of college students.

\section{Realization Path of the Cultivation of College Sports Spirit}

\subsection{Construct Sports Cultural Atmosphere}

As a kind of cultural spirit, sportsmanship exerts a subtle influence on human mind. It can exert a positive influence on students in many aspects of daily life. College sports need to create a good sports culture atmosphere, let students feel strong experience atmosphere, let the whole university can be filled with a warm sports spirit, constantly strengthen their sense of physical exercise, enhance students' interest in sports. The bearer of college sports spirit is students, and the creation and development of sports culture is also a student. Only when students really act, can we better demonstrate sports culture. For college students, the college has a good sports culture atmosphere, let the student receive the sports spirit, constantly stimulate their enthusiasm, induce students to experience the urge to exercise, develop good exercise habits, spirit and strength to the real perception of sports, to better inherit and carry forward the spirit of sports culture. College sports regularly carry out demonstration activities, the organization of teachers and students to carry out different specifications of the sports activities, organization of nonprofessional sports students to carry out various forms of sports competitions; encounter some major sports events in a timely manner to watch propaganda, universities have the school outdoor large screen direct broadcast Sports events for students to watch. Posting various forms of sports posters and sports culture publicity, let students feel the existence of sports culture everywhere, experience the power of sports spirit, and enhance their interest in experience. The most intuitive feeling and impression of students on sports facilities is their appearance and functional design. During their use, their colors, shapes and functions can be very intuitive to provide students with sensory experience. The stimulus of this sensory experience is fed back to the mind, which produces pleasure and enjoyment. Psychological pleasure and physical enjoyment further encourage students to integrate into sports activities more and longer, enjoying physical activity and physical and mental health while enjoying the process. Therefore, to promote the spirit of sports work in our school at the same time, and constantly improve the construction of sports facilities, sports facilities to increase infrastructure investment, and thus its rich sports facilities and the enjoyment of design beauty and rich and colorful campus environment, bring edification and enlighten their subtle goals. Colleges and universities should also transform their teaching ideas and concepts, really put students' physical education, intellectual education and aesthetic education in the same important position, carry forward the spirit of sports, and abandon the traditional educational thought of intellectual supremacy. Sports can ensure the strong health of the people and spirit can make people become gentle.

\subsection{Innovate Sports Teaching Methods}

The cultivation of sports spirit, teaching practice on education, in practice Chinese perception, strengthen training, the sports spirit is the quality of the students, now for their behavior and habits, let universities everywhere highlight the spirit of sports, college sports to become the most beautiful scenery, to create a more intuitive and rich sports cultural atmosphere. The target of education is divided into three levels of cognition, emotion and action, the cultivation of sports spirit can not only stay in the publicity and education, more important is the action and practice, through educational practice, the specific cognitive enhancement, enhanced experience, become a kind of comprehensive quality and ability. Let the students really develop their heart like sports, can take the initiative to 
participate in physical exercise, and truly perceive the charm and value of sports. To carry out rich and colorful sports activities, let students participate directly or watch sports, perception of beauty, manifested in sports competition and surpassing consciousness; establishing the sports of different interest groups, set up different project club, allowing students to spiritual and cultural perception of sports, learn different sports. The development becomes the individual's lifelong hobby, become a part of life and life. The highest goal of education is to realize the value of human beings. The goal of sports spirit is the spirit of giving support to the heart of the world, to achieve this goal, we must approach to education made the corresponding innovation and development with the development of the times, to promote the effective to stimulate students' enthusiasm for learning, and enhance students' self-perception ability. At present, to reflect the spirit of sports are mostly by all kinds of sports activities to be achieved, to the sports school students established sports associations, to students spontaneously organized sports activities, which are on the students' physical exercise has a positive effect.

\subsection{Improve Sports Management System}

The sports system must be perfected and perfected to vigorously promote the construction of the sports spirit. From the perspective of colleges and universities, we should carry out and implement the requirements and spirits of the school's cultivation of sports spirit, and realize that the cultivation of sports spirit is a long-term and arduous project, and it is also a long-term measure for college students to strengthen their physique and willpower and improve their personality. The relationship between the school grade project and the quality of the project, the quantity and quality of the activities, the physical quality of the students, the psychological quality and the comprehensive quality are properly dealt with. It is a strong guarantee for the promotion of sports spirit to improve the management system of school group sports work and establish and improve the rules and regulations of physical education. On this basis, the college takes the student union as the starting point, sets up a team for promoting sports spirit work, and sets up clubs, which effectively standardize and guarantee the effective promotion of sports spirit cultivation. The university sports competition should interact with and develop together with the campus sports culture construction. The interaction factors between the two include competition system, theoretical guidance, propaganda, school leaders, sports funds and so on. Through the investigation of the interaction between the sports competitions in colleges and universities in Shanxi and the construction of the campus sports culture, it is found that the interaction of the two is seriously missing. Sports competition in Colleges and universities is always the basis of the existence and development of campus culture, and the number of participants is also an important indicator of school physical education. It is found that most of the students' attitudes towards sports competition are willing, but the number of people who dislike it is also a proportion. This indicates that there is still a lack of enthusiasm for students and need further guidance.

\section{Conclusion}

In the daily life of college students' sports spirit everywhere, and it will also be on the development of students' life in the future will have a major impact. College students carrying the national rejuvenation and prosperity of the country's responsibility, they strengthen the cultivation of sports spirit will help to develop a sounder personality thought. Therefore, the integration of sports spirit education into university education will be an important aspect of the development of university education in the future, and it is also an inevitable requirement to adapt to the development of contemporary society.

\section{References}

[1] Li Guotai, Li Hui. The Lack and Recovery of College Sports Spirit [J]. Sports Science Research, 2016, 20(1): 74-78. 
[2] Wang Kun, Sun Kaihong, Ji Liu. Relationships between Achievement Goal Orientations and Multidimensional Sportsmanship Orientations among Young Athletes [J]. Journal of Shanghai University of Sport, 2015, 39(5): 53-56+70.

[3] Xu Jian. Socialist Core Values Education of Chinese Sports Spirit and College Students [J]. Hubei Sports Science, 2015, 34(3): 211-213+220.

[4] Yu Kehong, Zhang Qiao. A study of sports spirit and university spirit [J]. Journal of Physical Education, 2014, 21(3): 80-83. 